\title{
New techniques for early detection of lung cancer
}

\author{
G. Sutedja*
}

\begin{abstract}
New techniques for early detection of lung cancer. G. Sutedja. (C) ERS Journals Ltd 2003.

ABSTRACT: The resurgence of interest in lung cancer screening and the application of new techniques for the management of early cancer have raised various issues regarding this global epidemic. In previous randomised clinical trials, the use of conventional chest radiographs and sputum cytology examinations for screening have been shown not to reduce lung cancer mortality.

The use of biomolecular markers, autofluorescence bronchoscopy, low-dose spiral and high-resolution computed tomography, endobronchial ultrasonography, optical coherence tomography, confocal micro-endoscopy, positron emission tomography in combination with video-assisted thoracic surgery and intraluminal bronchoscopic treatments may provide new modalities with which to manage lung cancer at the earliest stage possible.

New hopes arise that the combined use of more accurate and minimally invasive diagnostic and treatment techniques may justify screening and reduce mortality. More individuals may also benefit, as many in the target population already suffer from poor cardiovascular and pulmonary health due to their smoking history and are considered at risk for surgical intervention. The cost-effectiveness of lung cancer screening will strongly depend on the proper selection of the target population and the optimal application of these new techniques.

Despite epidemiological controversy regarding lung cancer screening, the feasibility to define more precisely who are at risk and the use of less invasive techniques may preserve quality of life and improve the survival of many lung cancer patients.
\end{abstract}

Eur Respir J 2003; 21: Suppl. 39, 57s-66s.

\author{
Correspondence: G. Sutedja \\ Dept of Pulmonology \\ Vrije Universiteit Medical Center \\ PO Box 7057 \\ 1007 MB Amsterdam \\ The Netherlands \\ Fax: 31204444328 \\ E-mail: tg.sutedja@vumc.nl
}

Keywords: Early detection

early treatment

lung cancer

new techniques

\section{Received: July 92002}

Accepted after revision: September 25 2002
There is a resurgence of interest in lung cancer screening, as new technologies allow for a more precise definition of which people are at risk, enabling early detection to obtain stage shift and allow appropriate treatment at the earliest possible stage [1]. The lack of mortality reduction previously shown in randomised clinical trials (RCT) for lung cancer screening and recent analysis of the long-term outcome have led to hefty debates concerning whether it is currently appropriate to reconsider lung cancer screening in the general population [2-8].

Lung cancer morbidity is high and the cure rate is $<15 \%$ [9]. The majority of lung cancer patients are diagnosed at an advanced stage. Surgery provides the best chance for cure if a tumour can be completely resected in the absence of lymph node and distant metastases. Even after curative resection, many patients remain at risk for distant metastasis, local recurrence and the development of subsequent primaries [10-13]. Smoking-related problems, such as chronic obstructive pulmonary disease (COPD) and poor cardiovascular status, can limit the ability to apply the best treatment strategies because of unacceptable morbidity and mortality. Smoking behaviour and cancer susceptibility in certain individuals also explains why many will develop mutifocal cancers, a phenomenon known as field carcinogenesis [13-16]. The rate of second primaries is in the order of $1-2 \%$
[15]. An earlier study has shown a cumulative incidence for second primary cancer of up to $4 \%$ per year [13]. However, little is known about the natural history of cancer, i.e. carcinogenesis. Three pathways of preneoplastic lesions are currently recognised before lesions gradually progress towards squamous cell cancer (SCC), adenocarcinoma and neuroendocrine tumours [17-21]. Microinvasive SCC gradually develops from normal bronchial epithelium in a period of up to $10 \mathrm{yrs}$. SCC may be multifocal due to field carcinogenesis leading to the development of multiple synchronous or metachronous primaries [21]. Research to delay or reverse the gradual progression towards malignancy, e.g. chemoprevention strategies and molecular genetic studies, are being performed in many centres [1, 22, 23]. As inhaled carcinogens can lead to cumulative genetic damage in the bronchial epithelium of (ex)smokers, biomolecular studies to understand the sequence of genetic changes are important to identify those at greatest risk [24, 25]. The morphological changes seen through the various pre-invasive stages have been shown to be accompanied by more subtle genetic changes that are below the detection threshold of microscopic examination [24-29]. Patches containing 200-600 cells have been shown to harbour molecular changes, e.g. loss of heterozygosity or microsatellite alterations [28, 29]. Carcinoma in situ (CIS) consists 
of 4-38 cell layers and the majority of these lesions are about five cell layers thick. CIS lesions consist of noncircumferential patches, of several $\mathrm{mm}$ in magnitude, of atypical cells in the bronchial mucosa $[18,20]$. It is therefore obvious why conventional diagnostic tests such as chest radiographs, computed tomography (CT) scan and fibreoptic bronchoscopy (FB) have been insensitive for early detection and are not effective for early detection. Potentially malignant cell clones are far below the detection threshold of current diagnostic tests. It is paramount to develop more accurate and sensitive diagnostic tools for early detection and treatment.

Surgical resection and complete mediastinal lymph node dissection is the standard treatment of lung cancer. However, it remains a relatively morbid and wasteful treatment method for patients with central early stage cancer without nodal involvement, in whom superficial lesions are only several cell layers thick. As many patients may suffer from smokingrelated diseases, less morbid and tissue conserving therapeutic approaches are indispensable elements for a cost-effective screening programme $[30,31]$. Various aspects of new emerging technologies for early detection and treatment in lung cancer, mainly focusing on early SCC, will be discussed in this review.

\section{The target population}

Many Japanese centres have been conducting sputum cytology (and later on the use of low-dose spiral CT has been added to this programme) screening for decades $[32,33]$. Data have been consistent and in accordance with the Mayo screening study, showing that stage shift could be obtained. More cases of stage I-II squamous cancer amenable for surgical resection have been detected, leading to a higher resection and survival rate [34-37]. Individuals with early stage SCC in their central airways seemed to benefit most because they had sputum-positive but radiographically occult lung cancer (ROLC). This seems to be in contrast to subjects with sputumpositive adenocarcinoma, who were shown to have a poor survival, as $>82 \%$ of them were already in stage IIIA-IV [38]. Data from randomised clinical trials performed by the three institutions (Mayo Clinic, Rochester, MN, USA; Johns Hopkins, Baltimore MD, USA; and Memorial Sloan, Kettering, NY, USA) showed that in the cohort of subjects with SCC, more early cancers were detected and survival after resection was significantly better compared to those who refused surgery, $63-76 \%$ versus $<19 \%$, respectively $[4,39]$. Therefore, despite many controversies, early detection of SCC appears to be of some benefit if combined with surgical resection.

Extended follow-up data reconfirmed earlier findings that no mortality benefit exists, despite the significant survival advantage in resected early stage (squamous cell) cancer cohorts versus those who refused surgery $[2,4,6,39]$. Lung cancer proved not to be the major cause of death in the individuals screened $[4,40]$. The mortality of smokers from all causes of death is about three-fold more than nonsmokers. Mortality due to lung cancer was ultimately $7 \%$ in both arms of the Mayo study and SCC formed a minor cohort. Many individuals died due to other reasons, including ischemic heart disease and COPD. Case survival differences in the absence of mortality reduction have raised extensive debates about the real value of screening $[4,6-8,40,41]$. Overdiagnosis has been raised as an important problem of detecting relatively indolent cancers that would never have become clinically relevant. Some individuals are destined not to die from lung cancer per se, despite early detection and treatment. In the control arm of a screening study, the presence of lung cancer may remain undetected [41]. Two per cent of lung cancer cases were missed out of the 153 primaries found in a post-mortem study [42] and deaths in the screened arm from other causes may have been falsely attributed to lung cancer. Healthcare workers and individuals at risk strongly perceive that early detection and treatment can save lives, because lung cancer is assumed to be a fatal disease $[4,6,40]$. The inherent risks for mortality due to diseases such as COPD and cardiovascular diseases are competitive to lung cancer death as the ultimate cause. In retrospect, early lung cancer treatment may be regarded as treating a pseudo-disease. Screening may also lead to additional morbidity and mortality, which is not always expressed correctly in the number of diseasespecific mortalities. All these factors have led to different interpretations and controversies regarding the potential value of lung cancer screening [40, 41].

As it is currently still impossible to accurately predict the cause of death for each individual upfront, it is ethically difficult to refuse treatment in case early lung cancer is diagnosed. The lack of mortality benefit in previous RCTs, the issues of overdiagnosis and pseudo-disease may all be theoretically interesting, but they offer no solution in clinical practice [6]. In previous decades, advanced disease at presentation has been named as the major reason for the dismal cure rate of lung cancer patients. Despite all theoretical arguments about overdiagnosis and pseudodisease raised by the epidemiologists, a strategy of no treatment in a lung cancer screening trial will be unacceptable for clinicians.

The population cohort of (ex)smokers who have a $10 \%$ chance of developing lung cancer is very large. For peripheral early stage adenocarcinoma, a lobectomy and mediastinal lymph node dissection is the current standard of treatment [43, 44]. In contrast, intraluminal bronchoscopic treatment (IBT) provides an alternative for surgery for patients with central type early stage SCC [30, 31, 45]. The efficacy of this minimally invasive technique allows for the treatment of poor surgical candidates who were previously denied any screening because they were considered inoperable.

It is important to realise that forced expiratory volume in one second (FEV1), expressed as \% predicted, is prognostic for death from ischemic heart disease [46]. COPD with an FEV1 $<70 \%$ pred showed a 10-yr cumulative percentage for lung cancer death of 8.8 versus $2 \%$ for those with an FEV1 >85\% pred [47]. The difference in survival at $10 \mathrm{yrs}$ is 
significant, 74 versus $91.1 \%$, respectively. The higher relative risk for lung cancer in COPD smokers was significantly and proportionally related to the degree of airway obstruction, and the presence of ventilatory impairment was associated with a 6.44-times greater risk for lung cancer [48]. Paradoxically, screening of this population cohort may fuel more controversies regarding treatment of pseudo-diseases. Fortunately, IBT offers a less morbid treatment option to preserve quality of life, while it may significantly reduce the likelihood of dying from lung cancer $[30,31]$. Especially in this cohort of individuals, long-term local control to delay lung cancer death and not necessarily cure, may suffice to preserve quality of life. Therefore, the application of less invasive and morbid treatment methods has to be put into proper perspective.

Approximately $90 \%$ of (ex)smokers will not die because of lung cancer, therefore, a highly specific diagnostic test may allow the identification of the $\sim 10 \%$ cohort who have the greatest risk. Molecular epidemiology studying cancer susceptibility, e.g. CYP1A1, CYP2D6 and GSTM polymorphisms looking for an individual's capacity to detoxify carcinogens, has shown that the presence of null GSTM1 and mutant CYP1A1 genotypes were associated with a relative risk of 41 to develop lung cancer [49]. However, data have not been very consistent and a recent review by KIYOHARA et al. [50] about genetic polymorphisms and lung cancer susceptibility has addressed this conflicting issue. Their meta-analysis seemed to show only myeloperoxidase and microsomal epoxide hydrolase exon 4 polymorphisms to be significantly associated with lung cancer risk.

The combination of accurate diagnostic tests and minimally invasive treatment are crucial elements for cost-effective screening. Screening-related anxiety, morbidity and mortality may increase burden and costs. The efficacy of minimal invasive treatment, i.e. intraluminal bronchoscopic treatment, as an alternative to surgery, warrants the inclusion of the cohort population with severe COPD and poor general health, despite their inherent higher risk of dying from nonlung cancer-related diseases [30, 45]. It remains to be seen whether genetic susceptibility studies may help to achieve a more economical screening programme, instead of scrutinising all (ex)heavy smokers with or without pulmonary function impairment.

\section{Sputum cytology screening}

To detect early stage lung cancer, sputum cytology screening (SCS) and chest radiography (and later on low-dose spiral CT) have been performed in many centres [32, 33]. Epidemiologists, cytopathologists, molecular biologists, radiologists and surgical oncologists have been involved in the process to identify and treat those with early lung cancer. Individuals with suspicious sputum cytology (severe atypia or malignant cells) have been subjected to FB and further radiological staging [51]. Sputum cytology mainly detects SCC in the central airway. Treatments offered have been both surgical and bronchoscopic, e.g. photodynamic therapy [30, 32-38].

Positive sputum cytology for adenocarcinoma proved to be stage $\geqslant$ IIIA in $82.4 \%$ of cases [37]. Hence, low-dose spiral CT has been used to detect early stage parenchymal lesions. Data so far have shown that it is possible to obtain a significant stage shift for the detection of stage I/II adenocarcinoma in $>80 \%$ of cases $[33,52,53]$. However, screening with low-dose spiral CT has been extensively debated because of the controversies mentioned previously [5-8, 52-54]. In addition, initial data showed that $>50 \%$ of individuals had one or more noncalcified nodule(s) at baseline CT examination, rendering more diagnostic steps to be taken $[7,8,53,54]$. Compared to low-dose spiral CT, the "false-positive" rate of early detection for SCC of sputum cytology is very low. Recent data from the University of Colorado Specialized Programs of Research Excellence (SPORE) trial, conducted in COPD (ex)smokers, have shown that 103 (4.2\%) incident cancers developed among 2,441 individuals. This is seven times the incidence of the normal USA population [55].

Immunostaining with heterogeneous nuclear ribonuclear protein (hnRNP) A2/B1 [56], quantitative image cytometry by looking at malignant associated changes (MAC) using deoxyribonucleic acid (DNA) texture analysis of the cell nuclei [26] and molecular biological markers [1, 24-29] have revealed changes far in advance and below the detection threshold of morphological classification. Molecular abnormalities may already present prior to morphological changes, therefore, individuals with normal sputum cytology cannot be excluded when studying carcinogenesis. The costs of a screening programme may increase because a larger proportion of COPD (ex)smokers has to be followed. The dynamism of clonal cell changes has to be studied further. Genetic changes may also be inherent to senescence and clonal dynamism, due to continuous exposure of bronchial mucosa to irritants inducing nonspecific inflammatory dynamic changes. These changes have to be studied diligently for a prolonged period before concluding that they are related to carcinogenesis per se [27, 28, 57]. Currently, not a single set of biomarkers has emerged and can be used for accurate prediction of the development of lung cancer in any particular individual. Early molecular changes have been studied, in terms of field carcinogenesis, by looking at "normal" specimens collected from remote areas where the primary tumour was located [27, 28, 58, 59]. Changes were detected in about $50-60 \%$ of individuals, underscoring the limited knowledge about the dynamism of bronchial mucosa. Therefore, the value of biomarkers has to be tested prospectively in a larger cohort, comparing normal individuals, COPD, recurrent bronchitis, interstitial lung disease and those who, albeit analysed in retrospect, will develop lung cancer. Studies on archived sputum have shown sensitivities of MAC score (DNA texture analysis) and immunostaining with hnRNP A2/B1 to be 78 and $91 \%$, respectively $[26,56]$. The currently ongoing prospective study of Yunnan tin miners using immunostaining with hnRNP A2/B1 has again shown 
$80 \%$ sensitivity in those with lung cancer primaries and $78 \%$ sensitivity to predict those developing lung cancer [56]. More importantly, both MAC and immunostaining hnRNP A2/B1 seemed to result in a significant time shift forward, years in advance before lung cancer emerged. Semi-automated analysis of nuclear features for MAC has a sensitivity of $75 \%$ and a specificity of $90 \%[26,60]$. This allows unattended inspection of 50 slides daily. MAC DNA texture analysis is obviously consistent, excluding intra- and interindividual variability of the pathologists for classifying the degree of preneoplasia. Suspicious cells can be re-examined by the cytopathologist, as the exact co-ordinates of all cells can be digitally stored in a computer. It remains to be seen whether the use of biomarkers, immunostaining with hnRNP A2/B1 and automated sputum cytometry may reduce the range of subjective morphology classification and lead to a significant time shift forward in diagnosis. Currently, the large number of COPD (ex)smokers forms a major hurdle for the realisation of a cost-effective screening programme.

\section{Radiological examinations}

In previous trials, chest radiographs have been shown to be insensitive for detecting early parenchymal abnormalities and central airway tumours. Lesions $<1 \mathrm{~cm}$ in $70 \%$ of the cases were missed causing a diagnostic delay of $>1$ yr [61, 62]. Many parenchymal abnormalities were missed when analysed in retrospect. Hence, the use of low-dose spiral CT for early detection obtained a significant stage shift for stage I-II adenocarcinoma [33, 53]. This issue remains, however, controversial [5-8].

High-resolution CT improves staging accuracy prior to intraluminal bronchoscopic treatment in central early stage SCC [63]. One can exclude bronchial wall abnormalities indicating deeper tumour infiltration. The role of virtual bronchoscopy herein may be limited because of its finite spatial resolution to visualise minute mucosal abnormalities [64]. Indeed, small patches of 90,000 cells may prove to be a great challenge for accurate radiological imaging $[18,19,28]$. The role of multi-sclice CT herein has not been investigated.

\section{Bronchoscopy and autofluorescence bronchoscopy}

For SCC, cumulative genetic damages seem to correspond with the different grade of morphological changes, from low to high grade dysplasia (HGD) [1, 22, 24-29]. Morphologically, normal mucosa may already contain genetic abnormalities $[27,28]$. Stepwise histological changes are believed to occur from normal through the various grades of squamous metaplasia, mild, moderate and severe dysplasia, and CIS before the lesion becomes micro-invasive [18-21].

This seems compatible with the results of AUERBACH and co-workers $[18,20]$, who investigated the relationship between smoking and changes in bronchial epithelium. Post-mortem step sections of the entire tracheobronchial tree in 402 male patients were obtained, with up to 208 sections per individual. The true presence of CIS in particular was shown to correlate with smoking history and the presence of cancer. CIS lesions were found in $23(2.4 \%)$ of the 956 sections, showing atypical cells in the entire specimen, with an average depth of only five cells (range 4-38). In early SCC, $61 \%$ of the lesions had depth abnormalities of $\geqslant 6$ cell layers. Therefore, early SCC is indeed $<1 \mathrm{~mm}$ thick. Nonsmokers did not appear to harbour any CIS. CIS was present in $75 \%$ (27 of 36) of the subjects who smoked $\geqslant 2$ packs $\cdot$ day $^{-1}$ and in $83 \%$ (52 of 63 ) of lung cancer subjects. The presence of multiple CISs strongly supports field carcinogenesis, which was found in $11.4 \%$ of smokers smoking $\geqslant 2$ packs $\cdot$ day $^{-1}$ and in $15 \%$ of lung cancer patients.

However, the exact location of CIS using conventional FB could only be determined in $29 \%$ of the cases [13]. Two-thirds of these ROLC were shown to be a few mm thick. SATo et al. [65] reported that $527 \mathrm{FB}$ sessions were required to ultimately pinpoint the lesions in 180 patients with 200 occult cancers [65]. An average of three lengthy $\sim 45 \mathrm{~min}$ FB sessions was carried out, with separate brushings of all segments. In retrospect, 175 lesions were located proximal to the subsegmental bronchi, thus, within the visible range of the FB. Initial false-negative findings led to an average delay of 29.2 months.

Data clearly show that the lack of any instrument to locate these lesions will be counterproductive to the concept of stage shift. The accessibility of the entire bronchial tree is limited by the size of the bronchoscope and the use of an ultrathin bronchoscope for inspecting subsegmental branches up to the tenth generation may only increase the burden of bronchoscopic examination [66].

Laser induced fluorescence endoscope (AFBLIFER; Xillix, Richmond, BC, Canada) uses a helium-cadmium laser of $\lambda 442 \mathrm{~nm}$ for tissue excitation $[67,68]$. The emission spectrum is captured by two sensitive charged coupled device (CCD) cameras and processed through a fluorescence collection sensor and an optical multichannel analyser. Real-time digitised images are acquired by using ratios of red to green $(\lambda 630 \mathrm{~nm}$ to $\lambda 520 \mathrm{~nm})$ fluorescence emissions for correcting distance and movement during examinations. Special imaging algorithms have been generated, based on the data of in-vivo and in-vitro analysis, and Monte-Carlo simulation modelling [69]. Digitised images reflect the in-vivo fluorescence signals collected, exploiting the differences in autofluorescence characteristics between suspicious (HGD and CIS) and normal bronchial mucosa. The suspicious lesions appear red-brownish while normal mucosa appears green. Other systems use the fluorescencereflectance system in their imaging algorithms, such as the D-light system (Storz R); Karl Storz, Tüttlingen, Germany). A noncoherent ultraviolet to blue $300 \mathrm{~W}$ Xenon filtered lamp ( $\lambda 380-460 \mathrm{~nm}$ ) is used to excite a broad emission spectra of the different chromophores in tissue [70]. In combination with some reflectance of blue light, the D-light produces bluish 
images for normal areas and darker images for HGD and CIS. The SAFE R 1000 autofluorescence system (Pentax, Asahi Optical, Tokyo, Japan) also uses a Xenon-lamp ( $\lambda$ 420-480 nm) and the camera contains a fluorescence filter as well as an image intensifier [71]. Also soon, new fluorescence-reflectance imaging systems (ONCO-LIFE $\AA$, Xillix; Wolf $\AA$, Knittlingen, Germany) will enter clinical trials, with the aim to reduce equipment costs and to ease the autoflouresence bronchoscopy (AFB) procedure. Exploiting both quantitative and qualitative imaging algorithms may improve accuracy in differentiating true pre-invasive lesions from non-specific lesions, thus nonmalignant mucosal abnormalities.

Photodynamic diagnosis, using photosensitisers, has been used to enhance image contrast [70]. The relative selectivity of the photosensitising molecules for malignant tissue and the higher photon yield may abolish the need for expensive laser and ultrasensitive CCD cameras. However, the lack of drug selectivity, complex pharmacokinetics and skin photosensitivity raise issues as to whether this will be cost-effective and practical to be implemented for screening at large. McWilliams et al. [72] reported that the use of digitised fluorescence ratio, i.e. quantitative imaging projected on the monitor screen, increased CIS detection rate to the full $100 \%$ score.

AFB-LIFE programmes have so far included the largest number of individuals and thousands of lesions have been collected [73-75]. A panel of pathologists have reviewed all biopsy specimens for the proper World Health Organization (WHO)/International Association Study Lung Cancer (IASLC) classification, as intra- and interindividual variability of histology reporting is an important determinant of the results. AFB-LIFE in addition to the conventional method of FB has been shown to be $2-4$ fold more accurate to detect pre-invasive lesions (80-100\% range) [75]. The sequence of examinations and the individual bronchoscopist did not affect the results [76]. Unforeseen occult synchronous lesions were also found in $\sim 10 \%$ of the individuals with lung cancer primaries [77]. AFB-LIFE significantly improved the detection rate for angiogenic squamous dysplasia, an entity believed to be genetically important in the process of carcinogenesis [76, 78]. The additional use of AFB-LIFE for accurate staging helped define the best treatment approach in addition to highresolution CT, as only $25 \%$ of ROLCs were truly occult and amenable for IBT [79]. The use of AFB extended the duration of the FB session by $<15$ min [80]. Nevertheless, sensitivity, specificity and accuracy remain a relative issue, strongly dependent on the population studied. Smoking history [75], sex distribution (relative paucity of preneoplastic lesions in females [81]), the level of personal expertise of the bronchoscopist [68,73-75] and the intra- and interindividual variability of histology reporting [82-84] are all factors to be taken into account.

It has been commonly accepted that the WHO/ IASLC morphology criteria is the gold standard. However, even among experienced pathologists, full agreement of classifying malignancies may only reach a $\kappa$ value of 0.73 [82]. The reproducibility for classifying pre-invasive lesions showed intra-observer agreement of 0.71 and interobserver agreement was only 0.55 [83]. In classifying CIS in the current authors' initial study period, only $<50 \%$ were confirmed by the panel to have a CIS [84]. Intra- and interobserver variability in histology reports are easily overlooked and should be accounted for in analysing data of carcinogenesis studies, especially in looking at specific biomarkers that accompany these early morphological changes [1, 24-28]. By using the internet for more accurate morphological classification, a $\kappa$ value of 0.9 could be obtained [85].

Unfortunately, biopsy sampling using AFB-LIFE has been shown to remove the entire patch of clonal cells $[28,29]$. Many lesions were $<1.5 \mathrm{~mm}$ in diameter and $\sim 50 \%$ of these lesions were shown to be smaller than the size of the flexible biopsy forceps. Twentyseven of the 69 paired biopsies obtained at 6-month intervals showed one or more molecular changes in the initial biopsy specimens. However, $86 \%$ had no abnormality after rebiopsy and $24 \%$ lacked the initial changes found after repeat biopsy [29]. Therefore, the natural history of some lesions cannot be studied because of complete mechanical removal at baseline examination. Studying the natural history of minute pre-invasive lesions, especially at the earlier preinvasive stages may become virtually impossible.

Spectroscopic images obtain the entire spectral images of the target tissue within a wavelength of interest $[86,87]$. Optical coherence tomography (OCT) can record two-dimensional, cross-sectional images of cell layers [88]. Confocal micro-endoscopy provides cellular images to be used in studying carcinogenesis at the subcellular level [89]. By suppressing images that are out of focus, optical sectioning and three-dimensional reconstruction images can provide superimposed pictures on a microstructural level. New developments in optical biopsy techniques such as OCT and confocal micro-endoscopy may help in the understanding of the natural history of pre-invasive lesions, without the necessity of taking biopsy. However, until the exact algorithms for optical biopsy can be generated, some comparative studies using the WHO/IASLC morphological classification may be required.

The initial false-positive findings using AFB (suspicious fluorescence image but normal histology classification) have to be studied longitudinally. Genetic damages at multiple chromosomal sites (e.g. 3p14, $9 \mathrm{p} 21, \mathrm{p} 16$, etc.) have been reported in morphologically normal and minimally altered bronchial specimens. Increasing percentages of abnormalities were found in current smokers and subjects with a higher metaplasia index [27]. PARK et al. [28] showed the presence of (multifocal) molecular abnormalities $(3 p, 9 p, 17 q$ regions) in morphologically normal and pre-invasive lesions. Increasingly more changes from normal towards dysplastic foci were found [28]. In $68 \%$ (13 of 19) of the patients the specimens showed at least one abnormal focus among the seven chromosomal regions analysed. Heterogeneity was seen in the changes of molecular patterns and they were not necessarily identical with those in tumour clones. A more homogeneous allele-specific loss was found 
in materials sampled with the AFB-LIFE in their previous study. This suggests that abnormal fluorescence characteristics may represent a more malignant cohort of lesions than in samples collected by random biopsy alone. This seems compatible with the recent interpretation of angiogenic squamous dysplasia [78].

The availability of AFB-LIFE allows for longitudinal study, to exclude sampling bias, in studying the natural history of pre-invasive lesions. BотA et al. [90] recently reported a $6.1 \%$ progression rate among 147 dysplastic lesions, irrespective of whether individuals ceased smoking. Only $2.5 \%$ of the 359 lowgrade lesions progressed and only did so in the presence of a HGD. In 53 patients without HGD or invasive cancer, none of the low-grade lesions showed progression.

The current authors recently analysed the natural history of pre-invasive lesions [91]. Twelve per cent of the lesions progressed toward CIS or microinvasive SCC. The spontaneous regression rate was $88 \%$ and no stepwise pattern of morphological changes could be determined. The morphological changes over time were very dynamic in a nonstepwise manner. This was true for all lesions, whether they progressed, regressed or remained stable during follow-up. Progressive lesions were more likely in patients with COPD and after previous primaries. The dynamism of each lesion during follow-up makes it rather difficult to predict any outcome by using the initial morphological classification as a starting point. Therefore, the finding of any metaplasia or dysplasia in a transversal study cannot always be reliably used to predict the likelihood for cancer development in any particular individual. The current sampling method of bronchial tissues may contain many nonspecific clonal cell changes and disturb the natural history [57]. Nonspecific clonal polymorphisms in the samples collected in a transversal or longitudinal study may generate a high background noise for biomolecular studies, as $>80 \%$ of the specimens regressed spontaneously. From the data of both longitudinal studies [90, 91], the progression rate to malignancy of $6-12 \%$ seems compatible with the $10 \%$ rate lung cancer development in the population of smokers [17-20]. Recent data by LAM et al. [92] has shown that in the placebo arm of a chemopreventive agent (anethole dithiolethione) study in smokers, the rate of progression of dysplastic lesions was in the order of $17 \%$.

A follow-up study in individuals who ultimately developed CIS has been conducted with 3-4 monthly repeat AFB-LIFE, showing that all CIS ultimately progressed to SCC [93]. CIS seems to be the point of no return, therefore individuals with CIS should be treated promptly. The natural history of preneoplastic lesions have to be further investigated in combination with molecular genetics in a prospective fashion. Optical biopsy techniques may offer a solution to prevent tissue disturbance by taking biopsy, which may disrupt the natural history of these preinvasive lesions.

\section{How to treat early stage lesions}

The most important step prior to any treatment is accurate staging. "Early stage" SCC should be assessed with regard to tumour margins and depth of tumour invasion in the bronchial wall [13, 30, $31,45]$. Data of endobronchial ultrasonography have been consistent in terms of its spatial resolution, but it is somewhat early to definitely conclude its value practically $[94,95]$. The role of PET-scan for accurate staging of intraluminal tumour and to exclude nodal disease also warrants further investigation [96].

The importance of tumour microscopy and its nodal status can be reviewed from previous surgical series [34-37, 97-101]. Early detection and surgical resection in previous $\mathrm{RCT}$ achieved a 5-yr survival rate of 55 versus $26 \%$ in the control arm and the p-value was 0.032 [4]. It is important to realise that a subgroup of patients with early stage SCC harbour minute superficial and intraluminal lesions. Many phase II studies have dealt with the efficacy of IBT [30, 31, 45, 90, 93, 101-103]. Ideally, phase III studies comparing surgery versus various IBT modalities versus a no treatment arm are required. However, the relative paucity of early stage SCC, as many are detected by chance, makes the realisation of such a study difficult. Some individuals are considered poor surgical candidates (e.g. those with COPD, poor cardiovascular status, previously resected syn- and metachronous tumours). IBT is an alternative for surgery and is a parenchyma-conserving technique, provided staging is accurate to stage N0 tumour [45]. The choice of IBT modality is of less importance providing local staging has been accurate [101, 102].

Photodynamic therapy (PDT) uses injected photosensitisers, combined with laser illumination of the tumour area to obtain selective necrosis and has therefore been most popular for treating early stage SCC [30, 45, 103]. However, lack of selectivity for photosensitisers [87] and scar formation [102-104] do not support this theoretical advantage. All IBT modalities seem to be equally effective [31, 101]. Twenty-two out of 39 patients with early stage SCC were spared surgery after initial PDT treatment [45] and any IBT modality prior to surgery may allow for less extensive surgical resections [105-107]. IBT as the initial treatment strategy for intraluminal SCC is a prudent approach to preserve healthy lung tissue and quality of life $[45,79,93]$. In 32 patients considered nonsurgical candidates with central early stage SCC, the current authors' data showed that IBT could obtain excellent local control. Follow-up has been 2-10 yrs (median 5 yrs). Half of the patients are alive, and eight died due to recurrences of previous lung cancer primaries, although unrelated to the ROLC treatment. The remaining patients died of nonlung cancer-related causes [108].

\section{The costs of early intervention}

The present authors have calculated the cost of AFB-LIFE bronchoscopy for early intervention in a target population consisting of individuals with 
previously resected stage I-II NSCLC, ear nose and throat cancers, and positive sputum cytology. Twentyone lesions progressed to cancer (171 dysplastic lesions and 429 bronchoscopies). The tariff of one bronchoscopy examination in the Netherlands is 81 Euro. The endoscopic cost per cancer lesion found was 1,653 Euro. Treatment with electrocautery costs 380 Euro [101]. Thus, early bronchoscopic intervention per early stage SCC costs 2,033 Euro.

Longer follow-up is needed to definitely show the cost-effectiveness of early intervention in the "population at risk". From the bronchoscopist's point of view, a more pro-active role is warranted as early diagnosis, accurate staging and intraluminal bronchoscopic treatment may provide the best chance for cure when lung cancer is found at the carcinoma in situ stage. However, squamous cell cancer may take 10 yrs to develop and repeat diagnostic steps during follow-up increases costs. All controversial aspects mentioned previously should determine the exact value of screening, as increasingly more individuals with poor general condition can be treated using minimal invasive treatment such as bronchoscopic electrocautery [108]. Curative local treatment by intraluminal bronchoscopic treatment increases the risk of these particular individuals to die later from nonlung cancer-related diseases, hence the controversy about treating pseudo-diseases.

\section{References}

1. Hirsh FR, Franklin WA, Gazdar AF, Bunn PA. Early detection of lung cancer: Clinical perspectives of recent advances in biology and radiology. Clin Cancer Res 2001; 7: 5-22.

2. Melamed MR, Flehinger BJ, Zaman MB. Impact of early detection on the clinical course of lung cancer. Surg Clin North Am 1987; 67: 909-924.

3. Kubik A, Parkin DM, Khlat M, Erban J, Polak J, Adamek M. Lack of benefit from semi-annual screening for cancer of the lung: Follow-up report of a randomized controlled trial on population of highrisk males in Czechoslovakia. Int J Cancer 1990; 45: 26-33.

4. Marcus PM, Bergstrahl EJ, Fagerstrom RM, et al. Lung cancer mortality in the Mayo Lung Project: impact of extended follow-up. J Natl Cancer Inst 2000; 92: 1308-1316.

5. Patz EF, Goodman PC, Bepler G. Screening for lung cancer. NEJM 2000; 343: 1627-1633.

6. Strauss GM, Gleason RE, Sugarbaker DJ. Screening for lung cancer: Another look, a different view. Chest 1997; 111: 754-768.

7. Jett JR. Pro/con editorials spiral computed tomography screening for lung cancer is ready for prime time. Am J Respir Crit Care Med 2001; 163: 812-815.

8. Patz EF, Goodman PC. Low-dose spiral computed tomography screening for lung cancer: not ready for prime time. Am J Respir Crit Care Med 2001; 163: 812-815.

9. Greenlee RT, Hill-Horman MB, Murray $\mathrm{T}$, et al. Cancer statistics 2001. CA Cancer J Clin 2001; 51: 1536.
10. Feld R, Rubinstein LV, Weisenberger $\mathrm{TH}$, and the Lung Cancer Study Group. Sites of recurrence in resected stage I non-small-cell lung cancer. A guide for future studies. J Clin Oncol 1984; 2: 1352-1358.

11. Pairolero PC, William DE, Bergstrahl EJ, Piehler JM, Bernatz PE, Payne SW. Postsurgical stage I bronchogenic carcinoma: morbid implications of recurrent disease. Ann Thor Surg 1984; 38: 331-338.

12. Martini N, Bains MS, Burt ME. Incidence of local recurrence and second primary tumors in resected stage I lung cancer. J Thorac Cardiovasc Surg 1995; 109: 120-129.

13. Woolner LB, Fontana RS, Cortese DA. Roentgenographically occult lung cancer: Pathologic findings and frequency of multicentricity during a 10-year period. Mayo Clin Proc 1984; 59: 453-466.

14. Lippman SM, Hong WK. Second malignant tumors in head and neck squamous cell carcinoma: The overshadowing threat for patients with early-stage disease. Int J Radiat Oncol Biol Phys 1989; 17: 691-694.

15. Johnson BE. Second lung cancers in patients after treatment for an initial lung cancer. $J$ Natl Cancer Inst 1998; 90: 1335-1345.

16. Braun NM, Caporaso NE, Page WF, Hoover RN. Genetic component of lung cancer: cohort study of twins. Lancet 1994; 344: 440-443.

17. Slaughter D, Southwick HW, Smeijkal W. "Field cancerization" in oral stratified squamous epithelium. Cancer 1953; 6: 963-968.

18. Auerbach O, Stout AP, Hammond C, Garfinkel L. Changes in bronchial epithelium in relation to cigarette smoking and in relation to lung cancer. N Engl J Med 1961; 265: 253-268.

19. Saccomano G, Archer VE, Auerbach O, Saunders RP. Development of carcinoma of the lung as reflected in exfoliated cells. Cancer 1974; 33: 256-270.

20. Auerbach O, Hammond C, Garfinkel L. Changes in bronchial epithelium in relation to cigarette smoking 1955-1960 vs 1970-1977. N Engl J Med 1979; 300: 381-386.

21. Kerr KM. Pulmonary preinvasive neoplasia. J Clin Pathol 2001; 54: 257-271.

22. Minna JD. Molecular pathogenesis of lung cancer and the potential translational application of these results to the clinic. Lung Cancer 1997; 18: Suppl. 2, 73-74.

23. Lippman SM, Hong WK. The biology behind. Cancer prevention by delay. Clin Cancer Res 2002; 8: 305-313.

24. Thiberville L, Payne P, Vielkinds J, et al. Evidence of cumulative gene losses with progression of premalignant epithelial lesions to carcinoma of the bronchus. Cancer Res 1995; 55: 5133-5139.

25. Wistuba I, Behrens C, Milchgrub S, et al. Sequential molecular abnormalities are involved in the multistage development of squamous cell lung carcinoma. Oncogene 1999; 18: 643-650.

26. Payne PW, Sebo TJ. Doudkine A, et al. Sputum screening by quantitative microscopy: A reexamination of a portion of the National Cancer Institute Cooperative Early Lung Cancer Study. Mayo Clin Proc 1997; 72: 697-704.

27. Mao L, Lee JS, Kurie JM, et al. Clonal genetic alterations in the lungs of current and former smokers. J Natl Cancer Inst 1997; 89: 857-862.

28. Park IW, Wistuba II, Maitra A, et al. Multiple clonal abnormalities in the bronchial epithelium of patients with lung cancer. J Natl Cancer Inst 1999; 91: 18631868 . 
29. Gazdar A, Park I, Sood S, et al. Clonal patches of molecular changes in smoking damaged respiratory epithelium. Lung Cancer 2000; 29: S7.

30. Hayata Y, Kato H, Furuse K, Kusunoki Y, Suzuki S, Mimura S. Photodynamic therapy of 169 early stage cancers of the lung and oesophagus: a Japanese multicentre study. Laser Med Sci 1996; 11: 255-259.

31. Boxem TJ van, Venmans BJ, Postmus PE, Sutedja G. Curative endobronchial therapy in early-stage nonsmall cell lung cancer. J Bronchol 1999; 6: 198-206.

32. Hayata $\mathrm{Y}$, Funatsu $\mathrm{H}$, Kato $\mathrm{H}$. Results of lung cancer screening programs in Japan: Early detection and localization of lung tumors in high risk groups. In: Band PR, ed. Recent Results of Cancer Research. Vol 82. Heidelberg, Springer Berlin, 1982; pp. 179-186.

33. Kaneko M, Eguchi K, Ohmatsu H, et al. Peripheral lung cancer: Screening and detection with low-dose spiral CT versus radiography. Radiology 1996; 201: 798-802.

34. Saito Y, Nagamoto N, Ota S. Results of surgical treatment for roentgenographically occult bronchogenic squamous cell carcinoma. $J$ Thorac Cardiovasc Surg 1992; 104: 401-407.

35. Shimizu N, Ando A, Teramoto S, Moritani Y, Nishii $\mathrm{K}$. Outcome of patients with lung cancer detected via mass screening as compared to those presenting with symptoms. J Surg Oncol 1992; 50: 7-11.

36. Endo C, Sagawa M, Sato M, et al. What kind of hilar lung cancer can be a candidate for segmentectomy with curative intent? Retrospective clinicopathological study of completely resected roentgenographically occult bronchogenic squmous cell carcinoma. Lung Cancer 1998; 21: 93-97.

37. Koike $\mathrm{T}$, Terashima M, Takizawa $\mathrm{T}$, et al. The influence of lung cancer mass screening on surgical results. Lung Cancer 1999; 24: 75-80.

38. Miura H, Konaka C, Kawate N, Tsuchida T, Kato H. Sputum cytology-positive, bronchoscopically negative adenocarcinoma of the lung. Chest 1992; 192: 1328 1332.

39. Flehinger BJ, Kimmel M, Melamed MR. The effect of surgical treatment on survival from early lung cancer: The impact of screening. Chest 1992; 101: 1013-1018.

40. Black WC. Overdiagnosis: An underrecognized cause of confusion and harm in cancer screening. $J$ Natl Cancer Inst 2000; 92: 1280-1282.

41. Juffs HG, Tannock IF. Screening trials are even more difficult than we thought they were. $J$ Natl Cancer Inst 2002; 94: 156-157.

42. McFarlane MJ, Feinstein AR, Wells CK. Clinical features of lung cancer discovered as a postmortem "surprise". Chest 1986; 90: 520-523.

43. Ichinose Y, Yano T, Yokoyama H. The correlation between tumor size and lymphatic vessel invasion in resected peripheral stage I non-small cell lung cancer. J Thorac Cadiovasc Surg 1994; 108: 684-686.

44. Ginsberg RJ, Rubinstein LV. Randomized trial of lobectomy versus limited resection for T1N0 non-small cell lung cancer. Lung Cancer Study Group. Ann Thorac Surg 1995; 60: 6615-6623.

45. Cortese DA, Edell ES, Kinsey JH. Photodynamic therapy for early stage squamous cell carcinoma of the lung. Mayo Clin Proc 1997; 72: 595-602.

46. Schuneman HJ, Dorn J, Grant BJB, Winkelstein W, Trevison M. Pulmonary function is a long-term predictor of mortality in the general population. 29-year follow-up of the Buffalo Health Study. Chest 2000; 118: 656-664.

47. Skillrud DM, Offord KP, Miller RD. Higher risk of lung cancer in chronic obstructive pulmonary disease. Ann Int Med 1986; 105: 503-507.

48. Tockman MS, Anthonissen NR, Wright EC, Donithan MG, The Intermittent Positive Pressure Breathing Trial Group and the Johns Hopkins Lung Project For The Early Detection of Lung Cancer. Airways obstruction and the risk for lung cancer. Ann Int Med 1987; 106: 512-518.

49. Nakaichi K, Imai K, Hayashi S. Polymorphisms of the CYP1A1 and Glutathione S-tranferase genes associated with susceptibility to lung cancer in relation to cigarette dose in as Japanese population. Cancer Res 1993; 53: 2994-2999.

50. Kiyohara C, Otsu A, Shirakawa T, Fukuda S, Hopkin J. Genetic polymorphisms and lung cancer susceptibility: A review. Lung Cancer 2002; 37: 241-256.

51. Kato H, Horai T. A colour atlas of endoscopic diagnosis in early stage lung cancer. Wolfe, Aylesbury, England, 1992; p. 35.

52. Sone W, Takashima S, Li F, et al. Mass screening for lung cancer with mobile spiral computed tomography scanner. Lancet 1998; 351: 1242-1245.

53. Henschke CI, McCauley DI, Yankelevitz DF, et al. Early lung cancer action project: Overall design and findings from baseline screening. Lancet 1999; 354: 99 105.

54. van Klaveren RJ, Habbema JDF, Pedersen JH, de Koning HJ, Oudkerk M, Hoogsteden HC. Lung cancer screening by low-dose spiral computed tomography. Eur Respir J 2001; 18: 857-866.

55. Hirsch FR, Prindiville SA, Byers T, et al. Sputum cytology as a marker of risk for lung cancerpreliminary results from the University of Colorado high risk cohort study. http://www.asco.org.

56. Tockman MS, Mulshine JL, Piantadosi S, et al. Prospective detection of preclinical lung cancer: results from two studies of heterogeneous nuclear ribonucleoprotein A2/B1 overexpression. Clin Cancer Res 1997; 3: 2237-2246.

57. Hittelman WN. Clones and subclones in the lung cancer field. J Natl Cancer Inst 1999; 91: 1796-1799.

58. Ahrendt SA, Chow JT, Xu LH, et al. Molecular detection of tumor cells in bronchoalveolar lavage fluid from patients with early stage lung cancer. $J$ Natl Cancer Inst 1999; 91: 332-339.

59. Ikeda N, MacAulay C, Lam S, et al. Malignancy associated changes in bronchial epithelial cells and clinical application as a biomarker. Lung Cancer 1998; 19: 161-166.

60. Marek W, Kotschy-Lang N, Muti A, et al. Can semiautomated image cytometry on induced sputum become a screening tool for lung cancer. Eur Resp $J$ 2001; 18: 942-950.

61. Soda H, Tomita H, Kohno S, Oka M. Limitation of annual screening chest radiography for the diagnosis of lung cancer. A retrospective study. Cancer 1993; 72 : 2341-2346.

62. Quenkel GBA, Kessels AGH, Goei R, Engelshoven JMA. Miss rate of lung cancer on the chest radiography in clinical practice. Chest 1999; 115: 720-724.

63. Sutedja G, Golding RP, Postmus PE. HRCT in patients referred for intraluminal bronchoscopic 
therapy with curative intent. Eur Resp J 1996; 9: 10201023.

64. Aquino SL, Vining DJ. Virtual bronchoscopy. Clin Ches Med 1999; 20: 725-530.

65. Sato M, Saito Y, Usuda K, Takahashi S, Sagawa M, Fujimura S. Occult lung cancer beyond bronchoscopic visibility in sputum cytology positive patients. Lung Cancer 1998; 20: 17-24.

66. Tanaka M, Takizawa H, Satoh M, Okada Y, Yamasawa F, Umeda A. Assessment of an ultrathin bronchoscope that allows cytodiagnosis of small airways. Chest 1994; 106: 1443-1447.

67. Hung J, Lam S, LeRiche JC, Palcic B. Autofluorescence of normal and malignant bronchial tissue. Lasers Surg Med 1991; 11: 99-105.

68. Lam S, MacAulay C, Hung J, LeRiche JC, Profio AE, Palcic B. Detection of dysplasia and CIS with a lung imaging fluorescence endoscopy device. $J$ Thorac Cardiovasc Surg 1993; 105: 1035-1040.

69. Qu J, MacAulay C, Lam S, Palcic B. Laser-induced fluorescence spectroscopy at endoscopy: tissue optics, Monte Carlo modelling and in vivo measurements. Optical Engineering 1995; 34: 3334-3343.

70. Haussinger K, Pichler J, Stanzel F, et al. Autofluorescence bornchoscopy: the D-light system. In: Bolliger CT, Mathur PN, eds. Interventional bronchoscopy. Vol 30. Prog Respir Res Basel, Karger, 2000; pp. 243-252.

71. Kakihana M, Kim KI, Okunaka T, et al. Early detection of bronchial lesions using system of autofluorescence endoscopy (SAFE) 1000. Diagn Ther Endoscopy 1999; 5: 99-104.

72. McWilliams A, Le Riche J, MacAulay C, Lam S. Quantitative fluorescence bronchoscopy. IPA 8th World Congress of Photodynamic Medicine, Vancouver Canada, June 2001, Abstract P40. http://www.derm. ubc.ca/pdt2001/.

73. Lam S, Kennedy T, Unger M, et al. Localization of bronchial intraepithelial neoplastic lesions by fluorescence bronchoscopy. Chest 1998; 113: 696-702.

74. Thiberville, Sutedja G, Vermijlen P. A multicenter European study using the light induced fluorescence endoscopy system to detect precancerous lesions in high-risk individuals. Eur Resp J 1999; 14: 2475.

75. Sutedja G, Venmans BJ, Smit EF, Postmus PE. Fluorescence bronchoscopy for early detection of lung cancer. A clinical perspective. Lung Cancer 2001; 34: 157-168.

76. Hirsch FR, Prindiville SA, Miller YE, et al. Fluorescence versus white-light bronchoscopy for detection of preneoplastic lesions: a randomized study. J Natl Cancer Inst 2001; 93: 1385-1391.

77. Pierard P, Vermijlen P, Bosschaerts T, et al. Synchronous roentgenographically occult lung carcinoma in patients with resectable primary lung cancer. Chest 2000; 117: 779-785.

78. Keith RL, Miller YE, Genmill RM, et al. Angiogenic squamous dysplasia in bronchi of individuals at high risk for lung cancer. Clin Cancer Res 2000; 6: 16161625.

79. Sutedja G, Codrington H, Risse EK, et al. Autofluorescence bronchoscopy improves staging of radiograhically occult lung cancer and has an impact on therapeutic strategy. Chest 2001; 120: 1327-1332.

80. Venmans BJ, van Boxem TJ, Smit EF, Postmus PE, Sutedja G. Results of two years experience with fluorescence bronchoscopy in detection of preinvasive bronchial neoplasia. Diagn Ther Endoscopy 1999; 5: 77-84.

81. Lam S, LeRiche JC, Zheng Y, et al. Sex-related Differences in bronchial epithelial changes associated with tobacco smoking. J Natl Cancer Inst 1999; 91: 691-696.

82. Venmans BJ, Linden van der JC, Elbers JRJ, et al. Observer variability in histopathological reporting of bronchial biopsy specimens: influence on the results of AFB in detection of bronchial neoplasia. J Bronchol 2000; 7: 210-214.

83. Burnett RA, Howatson WR, Lang S, et al. Observer variability in histopathological reporting of non-small cell lung carcinoma on bronchial biopsy specimens. J Clin Pathol 1996; 49: 130-133.

84. Nicholson AG, Perry LJ, Cury PM, et al. Reproducibility of the WHO/IASLC grading system for preinvasive squamous lesions of the bronchus: A study of inter-observer and intra-observer variation. Histopathology 2001; 38: 202-208.

85. Hirsch FR, Gazdar AF, Gabrielson E, Lam S, Franklin WA. Histopathologic evaluation of premalignant and early malignant bronchial lesions: an interactive program based on internet digital images to improve WHO criteria for early diagnosis of lung cancer and for monitoring chemoprevention studies A SPORE collaborative project. Lung Cancer 2000; 29: Suppl. 2, 209.

86. Vo-Dinh T, Mathur PN. Optical diagnostic and therapeutic technologies in pulmonary medicine. In: Bolliger CT, Mathur PN, eds. Interventional bronchoscopy. Vol 30. Prog Respir Res Basel, Karger, 2000; pp. $267-279$

87. Wagnieres GA, Star WM, Wilson BC. In vivo fluorescence spectroscopy and imaging for oncological applications. Photochem Photobiol 1998; 68: 603-632.

88. Fujimoto JG. Optical coherence tomography for the diagnosis of neoplasia. Lung Cancer 2000; 29: Suppl. 2, 89.

89. MacAulay CE, Guillaud M, LeRiche J, et al. 2D and $3 \mathrm{D}$ quantitative microscopy for preinvasive lung cancer. Lung Cancer 2000; 29: Suppl. 1, 252.

90. Bota S, Auliac J-B, Paris C, et al. Follow-up of bronchial precancerous lesions and carcinoma in situ using fluorescence endoscopy. Am J Respir Crit Care Med 2001; 164: 1688-1693.

91. Breuer RH, Elzinga EH, Risse J, et al. The natural course of preneoplastic lesions in bronchial epithelium - A longitudinal study. Am J Resp Crit Care Med 2002; 165: A403.

92. Lam S, MacAulay C, LeRiche J, et al. A randomized phase Iib trial of anethole dithiolethione in smokers with bronchial dysplasia. J Natl Cancer Inst 2002; 94: 1001-1009.

93. Venmans BJ, van Boxem TJ, Smit EF, Postmus PE, Sutedja G. Outcome of bronchial CIS. Chest 2000; 117: $1472-1576$.

94. Baba M, Sekine Y, Suzuki M, et al. Correlation between endobronchial ultrasonography (EBUS) images and histologic findings in normal and tumorinvaded bronchial wall. Lung Cancer 2002; 35: 65-71.

95. Miyazu Y, Miyazawa T, Kurimoto N, Iwamoto Y, Kanoh K, Kohno N. Endobronchial ultrasonography in the assessment of centrally located early-stage lung cancer before photodynamic therapy. Am J Respir Crit Care Med 2002; 165: 832-837.

96. Herder GJ, Breuer RH, Comans EF, Risse EK, van 
Mourik JC, Postmus PE. Positron emission tomography scans can detect radiographically occult lung cancer in the central airways. J Clin Oncol 2001; 19: $4271-4272$.

97. Nagamoto N, Saito Y, Ohta S, et al. Relationship of lymph node metastasis to primary tumor size and microscopic appearance of roentgenographically occult lung cancer. Am J Surg Pathol 1989; 13: 1009-1013.

98. Usuda K, Saito Y, Nagamoto N, et al. Relation between bronchoscopic findings and tumor size of roentgenographically occult bronchogenic squamous cell carcinoma. J Thorac Cardiovasc Surg 1993; 106: 1098-1103.

99. Akaogi E, Ogawa I, Mitsui K, et al. Endoscopic criteria of early squamous cell carcinoma of the bronchus. Cancer 1994; 74: 3113-3117.

100. Nakamura H, Kawasaki N, Hagiwara M, Ogata A, Kato H. Endoscopic evaluation of centrally located early squamous cell carcinoma of the lung. Cancer 2001; 91: 1412-1147.

101. Sutedja G, van Boxem AJ, Postmus PE. The curative potential of intraluminal bronchoscopic treatment for early-stage non-small-cell lung cancer. Clinical Lung Cancer 2001; 2: 264-270.

102. van Boxem TJ, Westerga J, Venmans BJ, Sutedja G. Photodynamic therapy, Nd-YAG laser and electrocautery for treating early-stage intraluminal cancer. Which to choose? Lung Cancer 2001; 31: 31-36.

103. Sutedja G, Lam S, LeRiche JC, Postmus PE. Response and pattern of failure after photodynamic therapy for intraluminal stage I lung cancer. J Bronchology 1994; 1: 295-298.

104. Kawaguchi T, Furuse K, Kawahara M, Sutedja G. Histological examination of bronchial mucosa after photodynamic therapy showing no selectivity of effect between tumour and normal mucosa. Lasers Med Sci 1998; 13: 265-270.

105. Kato H, Konaka C, Ono J, Hayata Y. Preoperative laser photodynamic threapy in combination with operation in lung cancer. J Thorac Cardiovasc Surg 1985; 90: 420-429.

106. Shankar S, George PJ, Hetzel MR. Elective resection of tumours of the trachea and main carina after endoscopic laser therapy. Thorax 1990; 45: 493-495.

107. Sutedja G, Baris G, Zoetmulder F, van Zandwijk N. High dose rate brachytherapy improves resectability in squamous cell lung cancer. Chest 1992; 102: 308309.

108. Vonk Noordegraaf A, Postmus PE, Sutedja G. Bronchoscopic treatment of patients with radiographically occult lung cancer not eligible for surgical resection: A follow-up study. Lung Cancer 2003 (in press). 